\title{
Standard as the basis for a corrosion education and certification international. Establishment of an international guide standard for Corrosion Management in industry
}

\author{
Dipl.-Ing. Agatha Swierczynski* \\ DIN CERTCO Gesellschaft fuer Konformitaetsbewertung mbH, 12103 Berlin, Germany
}

\begin{abstract}
Corrosion is still responsible for large economic losses in many and very different industry sectors like e.g. marine, refinery and petrochemistry, oil and gas pipelines or of drinking water and appearing by hot gases and combustion products in steel and concrete constructions. There are only some examples chosen. The corrosion phenomena are still a huge astonishment because of some costly repair processes and because of large production losses. The corrosion control systems existing by now help to avoid or to minimize these losses but the question still is, if the existing control system can be working better or longer. If yes, what a key can optimize the corrosion protection depending on the sector's requirements.
\end{abstract}

\section{Corrosion Management}

Why an ISO Guide Standard for Corrosion Management could be the solution for the industry? The idea is to have a guide standard for all sectors of industry to educate the staff depends on its responsibility. On the other hand, the ISO Guide Standard could become the role of main standard for all institutions being involved in the corrosion protection from production until monitoring of life of steel objects in the locations of their destinations. A standard means that all institutions being involved in corrosion protection could have one guide to follow because of the corrosion work. It is important to develop the ISO Standard for Corrosion Management together within the industry sectors to put in this document the existing experience of many experts working since years successfully in this field [1].

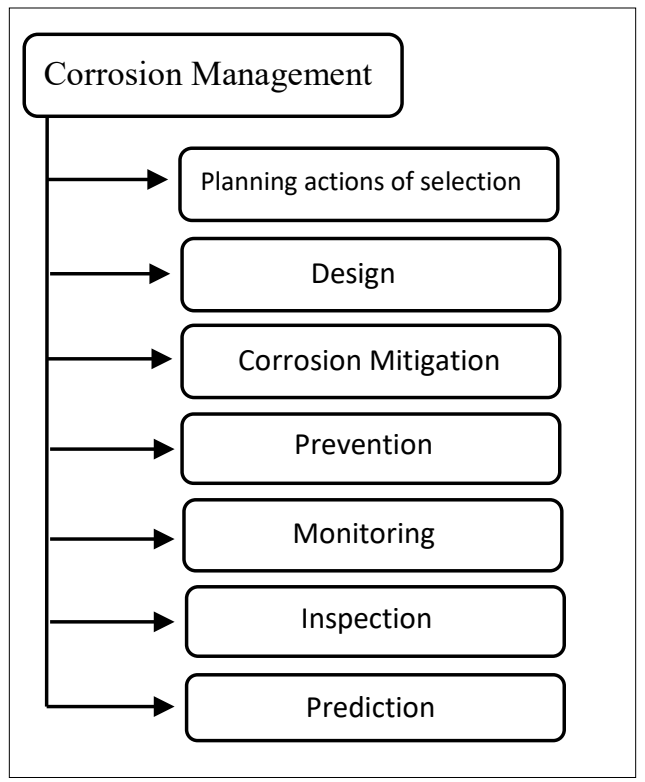

Fig. 1. Model of structure of Corrosion Management.

\subsection{Planning actions of selection}

The first step being important for the start with the corrosion protection is to plan right the actions obligatory. To plan the work with the object to be protected against corrosion and to plan the qualified staff to be responsible to work as constructors or inspectors with the object. Is it a new construction or is it an existing construction has to be monitored or maybe repaired or renewed in the location of work? Depends on the way to protect against corrosion its methods could be different. If the object in our focus is a new one, the design of it is the centre role and the start of corrosion protection, we could say the first step of the Corrosion Management. In other case, if the focused object has to be renewed, the centre role is the accurate monitoring including an inspection and prediction.

\subsection{Design}

The right design regarding corrosion protection is to construct an object in this way that the possibility that corrosion appears by working of this object in the location of destination will be minimalized. There are some characters to be managed as for example type of the object, the location of work and the environment there as well the destination, the material been used, in many cases including coatings, and the end of life planned in years, from low (L) until 7 years to very high (VH) more than 25 years [2]. There are so many requirements to be follow and to put them in one guide standard makes it easier to manage of corrosion.

\subsection{Corrosion Mitigation}

The understanding of corrosion phenomena based on the scientific studies should support the mitigation of corrosion. However, the corrosion mitigation can only work, if we observe that as complex system starting in

\footnotetext{
* Corresponding author: agatha.swierczynski@dincerto.de
} 
the design of steel objects after the selection of the best possible protection potential has been chosen. In this case, the guide ISO standard should be the source to verify any decision beginning with the planning action, discussed by design regarding mitigation of corrosion. Educated and qualified staff and experts in corrosion protection should support all steps until now.

\subsection{Prevention}

The prevention meaning to reduce the corrosion potential until minimum is an important part of Corrosion Management because of costs in case of necessary repairs or replacements, for example if the design of objects did not work right in the past. And it is not one reason only can appear. We should not forget that if we talk about objects being already used and therefore a part of steel constructions located in the industry. The enormous loses because of corrosion should be calculated right in each case before any action of selection starts. We should always focus to minimalize the costs by correct proceed. In this case, the ISO Guide Standard should include all needed available data and methods to prevent the corrosion and following to reduce the costs of repairs, replacements and of course, to inhibit any other kind of loses in the industry.

\subsection{Monitoring}

The role of monitoring is huge. Without monitoring, there were no data about progress of corrosion process in the life of steel object. The ISO Guide Standard should set requirements how the monitoring has to work. The employees should be educated in this case accurate to be able to handle with a clear line and to manage data efficiently. In focus of correct monitoring stand the competence of personnel and methods being available to take care of all actions within the Corrosion Management and this is a reason, why we need a standardized process to handle that in a possible precise and efficient way.

\subsection{Inspection}

The inspectors being responsible to decide about the life of steel objects bevor setting in the work location and after the elements are working already in their destinations, have an immense accountability. We can probably imagine how large a lost can be, if we have to work with staff without necessary qualification in the field as corrosion inspectors. The inspectors have a central role because they decide or support decisions about corrosion management beginning from inspection after production until end of life of steel elements in the locations of work. The inspectors manage the corrosion in the practice by setting of coatings, by repairs on working constructions, by taking decisions about replacement of elements. These people need in their practice the support, beginning from the design of constructions, by managing of data about corrosion and availability of methods and tools being necessary.

\subsection{Prediction}

The prediction can only work, when all others steps are working. We have to understand the protection against corrosion as a complex system involving the available knowledge, available methods and managing available educated staff responsible for corrosion protection. Beginning from managers planning industry objects, constructors being responsible for the design of steel elements, workers taking care of prevention during production process, inspectors controlling and being responsible for approval as well taking care of the monitoring during the life of objects until their end of life. This system of knowledge, methods and personnel can work and be efficient if it bases on a standard for the standardized process in its each phase of handling. This available knowledge, the available currently methods and the defined responsibilities of personnel should be summarized in one document with the status of an ISO Guide Standard for Corrosion Management in industry. A standard being available and used worldwide for one system of corrosion protection in all industry sectors. This standard should become the function of mandatory application in any industry and any enterprise. The government should approve the ISO Guide Standard for Corrosion Management as legislation with the effect that any noncompliance with the standard must punish by a fine [1].

\section{Legislation}

Developing of an ISO Guide Standard for the Corrosion Management is very important for the industry. The right way to work with the Guide Standard is to define this standard as mandatory. This responsibility to decide it as legislation has the Government. There can be some sectors being interested in. For example, Ministry of Environment, Ministry of Economy or as well the Ministry of Infrastructure, Industry and Energy.

The benefit for the Ministry of Environment could be the reduction of a risk of environment contamination, which can be reduced in significant way, if steel construction, for example pipelines, are monitored by educated and qualified staff only and in the right time. This can minimalize any accident being responsible for any nature catastrophe or being unhealthy for the environment, as well to all, by corrosion process and the corresponding damages in the constructions having a consequence for animate beings.

Each accident in the industry can cause large costs for the Ministry of Economy. In case of budgets being caused by corrosion, we talk about costs can be surely minimalized by accurate, careful and correct corrosion protection done by educated staff starting with the adequate design until the monitoring of steel elements in the industry until their end of life. Planning of new infrastructures or elements in the national economy focusing industry or energy sector, also some sectors being strategic for each country to secure own development, needs support of qualified staff to trust in 
their knowledge and skills. The knowledge and the skills have to be continuously updated in accordance with the ISO Guide Standard for Corrosion Management. This is a process involving many institutions being active in the field of corrosion protection. They are a part of corrosion management in the world.

\section{Education and certification}

How organise the education? Moreover, why we need a person certification? In each case been working with a standard it is important to use the standard in the same way. In this case, if we would like to educate the staff according to a standard we have to take care that the education will have still the same level, the material to learn has to be always updated and the teachers adequate qualified. Only in this way, we guaranty the right usage of the ISO Guide Standard for Corrosion Management. From other point of view, it is important that the staff being educated should be able to document its knowledge and skills in one way to keep the overview of the educated qualification. A pool with existing experts for corrosion protection depend on their qualification, like for example for planning actions of selection, for design of steel constructions, monitoring and others could be managed by one organisation worldwide by documentation of qualification and responsibility with the authorisation of the legislation because of the mandatory usage of the ISO Guide Standard for Corrosion Management in industry.

\section{References}

1. Dr. A. Groysman, Technion - The Israel Institute of Technology, Haifa and Israeli Society of Chemical Engineers and Chemists, Tel Aviv. Presentation about Corrosion Management during the EFC Conference in Cracow (2018)

2. DIN EN ISO 12944-1 - Corrosion protection of steel structures by protective paint system - Part 1 : General introduction (ISO 12944-1 :2017) 